\title{
Adaptation of Dominant Species to Drought in the Inner Mongolia Grassland - Species Level and Functional Type Level Analysis
}

\section{OPEN ACCESS}

Edited by:

Zhiyou Yuan,

Northwest A\&F University, China

Reviewed by:

Alexander Buyantuev,

University at Albany, United States

Jianyang Xia,

East China Normal University, China

Zhengwen Wang,

Institute of Applied Ecology (CAS),

China

*Correspondence:

Qing Zhang

qzhang82@163.com

Yong Ding

dingyong228@126.com

Yuanheng $L$

nmglyh@hotmail.com

Specialty section:

This article was submitted to

Plant Abiotic Stress,

a section of the journal

Frontiers in Plant Science

Received: 31 August 2018

Accepted: 11 February 2019

Published: 16 April 2019

Citation:

Yan Y, Liu Q, Zhang Q, Ding Y and Li Y (2019) Adaptation of Dominant

Species to Drought in the Inner Mongolia Grassland - Species Level and Functional Type Level Analysis. Front. Plant Sci. 10:231.

doi: 10.3389/fpls.2019.00231

\begin{abstract}
Yongzhi Yan ${ }^{1}$, Qingfu Liu1,2, Qing Zhang ${ }^{1 *}$, Yong Ding ${ }^{3 *}$ and Yuanheng Li $^{3 *}$
${ }^{1}$ Ministry of Education Key Laboratory of Ecology and Resource Use of the Mongolian Plateau, School of Ecology and Environment, Inner Mongolia University, Hohhot, China, ${ }^{2}$ Center for Biodiversity Dynamics in a Changing World, BIOCHANGE, Aarhus University, Aarhus, Denmark, ${ }^{3}$ Institute of Grassland Research, Chinese Academy of Agricultural Sciences, Hohhot, China
\end{abstract}

The adaptation of plants to drought through the adjustment of their leaf functional traits is a hot topic in plant ecology. However, while there is a good understanding of how individual species adapt to drought in this way, the way in which different functional types adapt to drought along a precipitation gradient remains poorly understood. In this study, we sampled 22 sites along a precipitation gradient in the Inner Mongolia grassland and measured eight leaf functional traits across 39 dominant species to determine the adaptive strategies of plant leaves to drought at the species and plant functional type levels. We found that leaf functional traits were mainly influenced by both aridity and phylogeny at the species level. There were four types of leaf adaptations to drought at the functional type level: adjusting the carbon-nitrogen ratio, the specific leaf area, the nitrogen content, and the specific leaf area and leaf nitrogen content simultaneously. These findings indicate that there is the trade-offs relationship between water and nitrogen acquisition as the level of drought increases, which is consistent with the worldwide leaf economics spectrum. In this study, we highlighted that the leaf economic spectrum can be adopted to reveal the adaptations of plants to drought in the Inner Mongolia grassland.

\section{Keywords: drought, plant functional type, leaf economic spectrum, inner mongolia grassland, adaptation strategy}

\section{INTRODUCTION}

Arid and semi-arid regions occupy approximately $45 \%$ of the Earth's land area and feed $38 \%$ of its population but also include some of the most vulnerable ecosystems and water resource systems (Narisma et al., 2007). In these regions, plant diversity maintains the ecosystem processes and functions and also affects ecosystem services (Balvanera et al., 2006). Water as the main limiting factor in these regions is one of the most important abiotic stresses influencing the survival, growth and distribution of plants. Therefore, the adaptation of plants to drought has always been a hot topic in ecological research (Chaves et al., 2002; Shavrukov et al., 2017). The characteristics of leaves are essential for the adaptation of plants to environmental change as leaves not only exhibit strong sensitivity and plasticity to spatial and temporal changes in the environment but can also improve the adaptability of plants through self-regulation (Picotte et al., 2009; Zhang et al., 2018). Therefore, 
the adaptation of plants to drought through the adjustment of leaf morphology has received much attention (Stropp et al., 2017).

Plant leaf exhibit both morphological and anatomical adaptations to drought. For example, plants that have grown under water-deficient conditions for a long period of time produce thickened, smaller leaves with a cracked appearance and a small specific leaf area, among other characteristics. Indeed, the leaves of some xerophytes become fleshy or even degenerate into rods. Such characteristics are conducive to reducing transpiration and promoting more effective heat dissipation (Bosabalidis and Kofidis, 2002; Stropp et al., 2017). In addition, plant leaves exhibit physiological and stoichiometric changes under drought conditions. For example, the photosynthetic rate may decrease as the level of drought increases (Tanaka and Shiraiwa, 2009). Furthermore, changes in the photosynthetic rate will further affect the uptake and recycling of nutrient elements and eventually lead to changes in the ecological stoichiometric characteristics of the leaves (Yuan et al., 2006; Zhang et al., 2018). He and Dijkstra (2014) experimentally showed that drought has a significant negative effect on plant nitrogen and phosphorus contents and a positive effect on the plant nitrogen-phosphorus ratio, while other experiments have shown that moderate drought stress may increase the uptake of nitrogen and decrease the growth rate of plants, resulting in a decrease in the carbon-nitrogen ratio (Lu et al., 2009).

Wright et al. (2004) proposed the concept of "leaf economics spectrum" (LES), which is a universal spectrum consisting of key leaf chemical, structural and physiological traits. At one end of the LES are species that have a "rapid investmentreturn" strategy, i.e., species with high leaf nitrogen contents, photosynthetic rates and respiration rates, short life spans and low specific leaf weights, while at the other end are species that have a "slow investment-return" strategy, i.e., species with long life span, large specific leaf weight, low nitrogen content, photosynthetic rate and respiration rate (Osnas et al., 2013). The resource trade-offs strategy is an important mechanism for LES, whereby plants that invest more resources in a particular functional trait will inevitably reduce the input of resources into other traits due to the total amount of resources that are available to the plants being limited, and such a trade-offs strategy has provided a mechanism by which plants can adapt to the environment in different geographical regions and ecosystems (Wright et al., 2005; Shipley et al., 2006; Ocheltree et al., 2016). Zhang et al. (2017) found that the trade-offs strategy of hydrophytes functional traits coincided with the worldwide LES. Abrahamson (2007) found that both Serenoa repens and Sabal etonia used a trade-offs strategy for functional traits under drought conditions, such as miniature plant morphology, a relative decrease in leaf size, number and photosynthetic yield, and prolonged leaf longevity, observing significant correlations among these traits and the formation of a continuously changing trade-offs strategy zone with the same plant species and homologous plants growing in shady or humid areas. Lohbeck et al. (2013) found that the trade-offs strategy is important for functional composition changes with succession in the dry and wet forest.

Studies that focus on characteristics of leaves of individual single species under different environmental conditions are important for revealing specific adaptive strategies at the species level (Zhu et al., 2012; Ramirez-Valiente et al., 2015; Liu et al., 2018). However, to generalized the plant adaptive strategies and the effects of global climate change on ecosystems, it is essential to group vegetation that is ecologically similar. The plant functional type is an assemblage of plants that share a set of key functional traits, respond to the environment in equal ways and play similar roles in the main ecosystem processes, (Chapin et al., 1996; Semenova and van der Maarel, 2000) and it has been shown that adaptive mechanisms often vary at the species and plant functional type levels (Domínguez et al., 2012). Although the environment is considered a key factor affecting leaf functional traits at the species level (Albert et al., 2010; Bu et al., 2017), the phylogenetic relationship among different species should also be considered because species with similar phylogenetic relationship may have similar functional traits (Kaplan and Pigliucci, 2001; Webb et al., 2002; Grether, 2005; Losos, 2008). In contrast, some studies have shown that plant functional types are the consequence of the adaptive processes of plants rather than branching processes in plant lineage (Pie and Weitz, 2005; Silva and Batalha, 2011). Thus, plant functional types can represent different adaptive strategies and may thus represent an efficient tool for revealing patterns of adaptation to environmental change (Ian and Wolgang, 2010). Moreover, understanding what adaptive strategies allow plants to successfully pass through the filter along an environmental gradient is of major importance in ecology. Moreover, understanding what adaptation strategies allow plant to pass through filter along the environment gradient successfully is a major issue in ecology.

The Inner Mongolia Plateau is a typical arid and semi-arid region with a large spatial precipitation gradient, making it an ideal place to study the adaptive mechanisms of plants to drought (Wu et al., 2015). In this study, we sampled 22 sites along the precipitation gradient of the Inner Mongolia grassland and measured eight leaf functional traits in 39 dominant species to address the following questions: (1) How are plants adapted to drought by modifying their leaf functional traits at the species and plant functional type levels? (2) Is the LES existing and applied to the adaptation of plants to drought in the Inner Mongolia grassland?

\section{MATERIALS AND METHODS}

\section{Study Sites}

This study was conducted across the entire area of the Inner Mongolia grassland in northern China, which stretches from $41.31^{\circ} \mathrm{N}$ to $50.78^{\circ} \mathrm{N}$ and $108.16^{\circ} \mathrm{E}$ to $120.39^{\circ} \mathrm{E}$ and has an elevation ranging from 532 to $1725 \mathrm{~m}$ above sea level (Figure 1). The typical landforms in this region include gently rolling plains, tablelands, and hills. The mean annual temperature ranges from -3.0 to $6.7^{\circ} \mathrm{C}$ and the mean annual precipitation varies from approximately 150 to $450 \mathrm{~mm}$, decreasing from the southeast to 


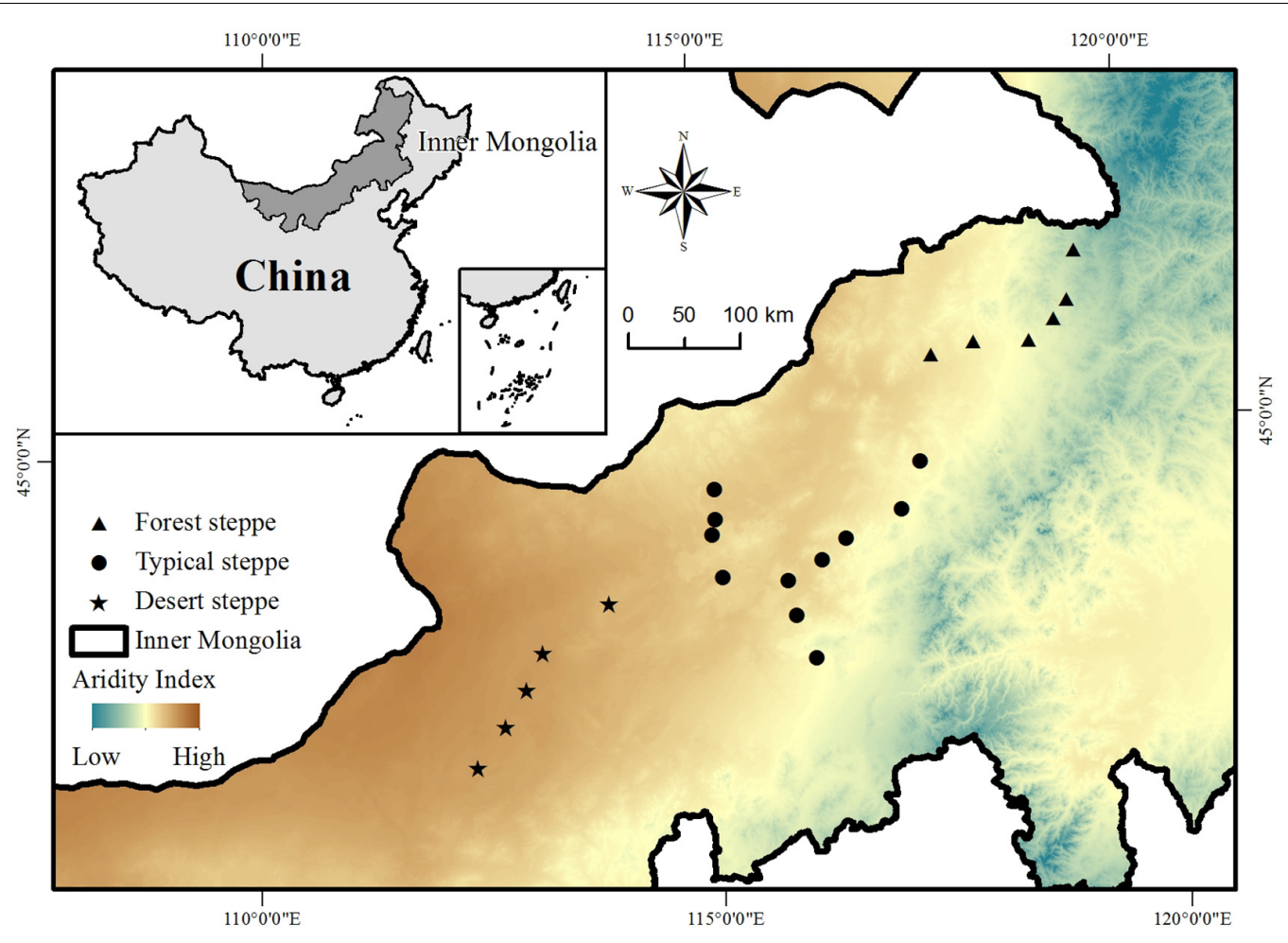

FIGURE 1 | Study area and sites.

the northwest (Inner Mongolia-Ningxia Joint Inspection Group of Chinese Sciences of Academy, 1985). The aridity at each study site (see below) was calculated as [1 - precipitation/potential evapotranspiration] (Delgado-Baquerizo et al., 2013). Along the climate gradient from the relatively humid southeast to the relatively dry northwest, there is a succession of soil types from chernozems to chestnut and calcic brown soils, and a succession of habitat types from forest steppe through to typical steppe and desert steppe grassland (Figure 1).

\section{Data Collection}

We surveyed 22 sites across the Inner Mongolia grassland in August 2017 during the peak period of aboveground biomass for the three main vegetation types: forest steppe, typical steppe, and desert steppe. The study sites had been banned grazing for over 3 years to minimize the potential effects of grazers and other disturbances. Five $1 \times 1 \mathrm{~m}^{2}$ quadrats were randomly set at each site and species within each quadrat were recorded. The functional traits were then recorded for all healthy and pestfree plants of each of the species found at each site following the standard measurement methods for plant functional traits (Cornelissen et al., 2003). Five individuals of each species with good vigor and no pests or diseases were selected in each quadrat and eight functional traits that are sensitive to environmental change were measured on three intact leaves per plant. The leaf area (LA) was measured using a leaf area meter (LI3100 Area Meter; LI-COR, Lincoln, United States). The leaves were then oven-dried at $60^{\circ} \mathrm{C}$ to obtain the leaf dry weight
(LDM). The specific leaf area (SLA) was calculated based on the leaf area and leaf dry weight. The leaf nitrogen and carbon contents (LNC, LCC) were measured with an elemental analyzer (Euro Vector EA3000; Milan), and the carbon-nitrogen (LC:N) and nitrogen-phosphorus ratios (LN:P) calculated. Finally, the total leaf phosphorus content (LPC) was determined using the ammonium molybdate spectrophotometric method (Bowman, 1988). The average values of the functional traits of each species at their respective sites were used in this study.

\section{Statistical Analyses}

We selected 39 species that had more than three occurrences across the entire sites for analysis. At the species level, we used the generalized linear model (Poisson distribution) to analyze the variation of eight plant functional traits that explained by climate (aridity) and phylogeny (genus). To analyze the respective and common interpretations of climate and phylogeny for each functional trait, we constructed three generalized linear models that included the trait as the response variable and aridity, genus, both aridity and genus as the explanatory variables, respectively. Thus, the $R^{2}$ values of the first and second models represented the amount of variation in a particular functional trait that explained by aridity and phylogeny, respectively, while the difference in the $R^{2}$ values between the sum of the first and second models and the third model indicated the combined effect of aridity and phylogeny on the each functional trait.

To analysis the adaptation of these species to drought at the plant functional type level, we first defined the plant functional 
types using cluster analysis (Semenova and van der Maarel, 2000). We constructed the clustering tree based on the Euclidean distance calculated using the eight functional traits of each species, each of which was first standard (Chapin et al., 1996; Montes-Pulido et al., 2017). Once the 39 species had been divided into functional groups, one-way ANOVA and multiple comparisons were performed to examine the differences in the eight functional traits between the functional types. To evaluate how each of the plant functional types adapted to drought, the direct relationship between aridity and the proportion of each functional type at a site was assessed by Pearson correlation analysis and ordinary least squares regression analysis, in which the proportion of plant functional types was represented by the ratio of the number of species which belongs to a given functional type to the total number of species at the site. Finally, to reveal how the different plant functional types successfully passed through the drought filter along the precipitation gradient and adapted to drought in the Inner Mongolia grassland, we used structural equation model to assess the causal relationships between aridity, the mean functional traits of the plant functional types and the proportion of plant functional types at a site using standardized path coefficients.

The generalized linear model, Pearson correlation analysis, one-way ANOVA, ordinary least squares regression and cluster analysis were conducted in $\mathrm{R}$ version 3.5.1. The structural equation model was conducted using the AMOS software. Shapiro-Wilk test was used to test the normality of the data before analysis and a log-normal transformation was used to normalize any variables that did not conform to the normal distribution.

\section{RESULTS}

\section{Effects of Aridity and Phylogeny on Variation in Plant Functional Traits at the Species Level}

Both aridity and phylogeny had significant effects on plant leaf functional traits, with variation in the leaf area, specific leaf area

TABLE 1 | Amount of variation in the leaf functional traits explained by phylogeny and aridity at the species level.

\begin{tabular}{lccc}
\hline Plant functional trait & Phylogeny (\%) & Aridity (\%) & $\begin{array}{c}\text { Phylogeny } \\
\text { and aridity } \\
\text { (\%) }\end{array}$ \\
\hline Single leaf area & $22.88^{*}$ & $12.51^{*}$ & 2.26 \\
Dry weight of single leaf & 24.76 & 7.20 & 2.05 \\
Specific leaf area & $0.40^{*}$ & $22.32^{*}$ & 0.39 \\
Leaf carbon & 0.23 & $1.99^{*}$ & 0 \\
Leaf nitrogen & 1.70 & 5.00 & 0.98 \\
Leaf phosphorus & 0.14 & 0.99 & 0.11 \\
Leaf carbon-nitrogen ratio & $2.57^{*}$ & $9.78^{*}$ & 1.44 \\
Leaf nitrogen-phosphorus & 0.04 & 1.55 & 0.04 \\
ratio & & & \\
\hline
\end{tabular}

${ }^{*} p<0.05$. and leaf carbon-nitrogen ratio being explained by both factors together, and variation in the leaf carbon content being explained only by aridity (Table $\mathbf{1}$ ).

\section{Classification of Plant Functional Types}

The 39 plant species analyzed could be divided into five functional types based on the eight functional traits measured (Figure 2). The differences in the eight functional traits among the five functional types are shown in Figure 3. Functional type III had a significantly higher single leaf area (Figure 3A) and leaf dry weight (Figure 3B) than the other four types, while functional type $\mathrm{V}$ had a significantly higher specific leaf area (Figure 3C). In terms of the leaf carbon content, functional type IV had significantly higher levels than functional type I but there was no significant difference among the other three functional types (Figure 3D), while for leaf nitrogen content, functional types I and II had remarkably higher levels than the other three functional types (Figure 3E). For the leaf phosphorus content, functional type II had much higher levels than the other four functional types and functional type IV had the lowest level (Figure 3F). With respect to the leaf carbon-nitrogen ratio, functional types III, IV, and V had higher values than functional types I and II (Figure 3G), while for the leaf nitrogen-phosphorus ratio, functional types $I$ and IV had much higher values than functional types II and V, with no significant difference being observed between functional type III and any other functional type (Figure $3 \mathbf{H}$ ).

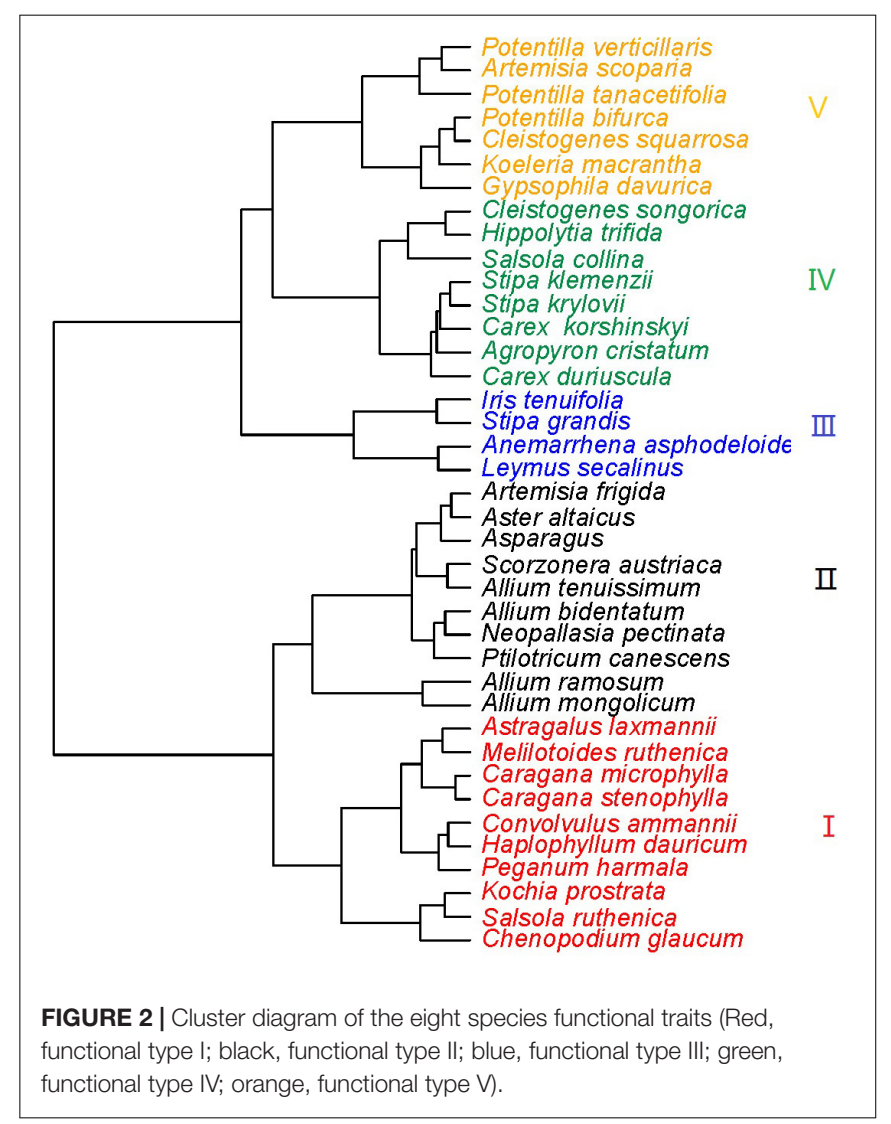



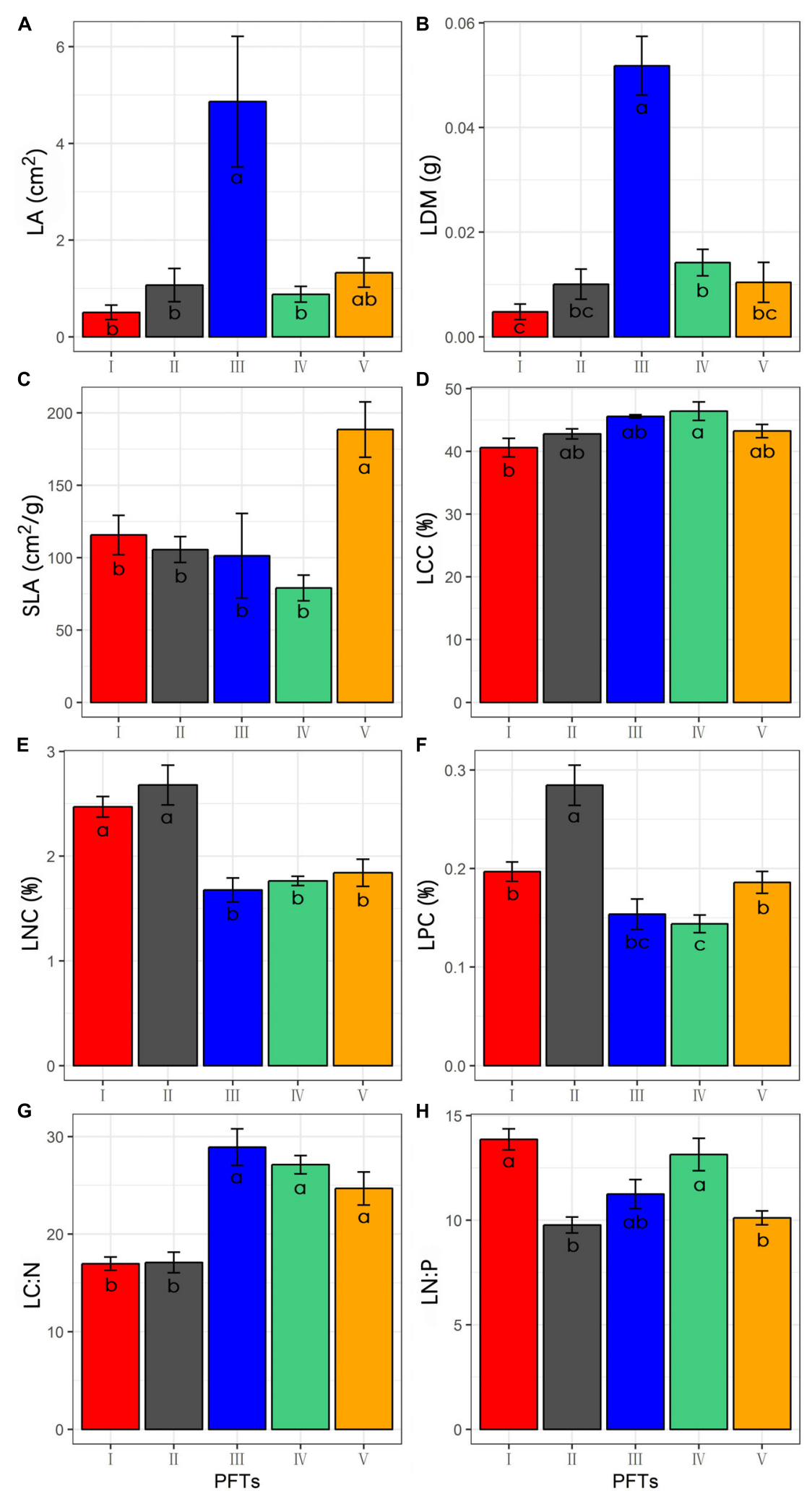

FIGURE 3 | Differences of functional traits among the five functional types (Data are the means and SE of eight functional traits in each of the five functional types). (A) Difference of the leaf area; (B) difference of the leaf dry weight; (C) difference of the specific leaf area; (D) difference of the leaf carbon content; (E) difference of the leaf nitrogen content; $\mathbf{( F )}$ difference of the leaf phosphorus content; $\mathbf{( G )}$ difference of the leaf carbon-nitrogen ratio; $(\mathbf{H})$ difference of the leaf nitrogen-phosphorus ratio. 


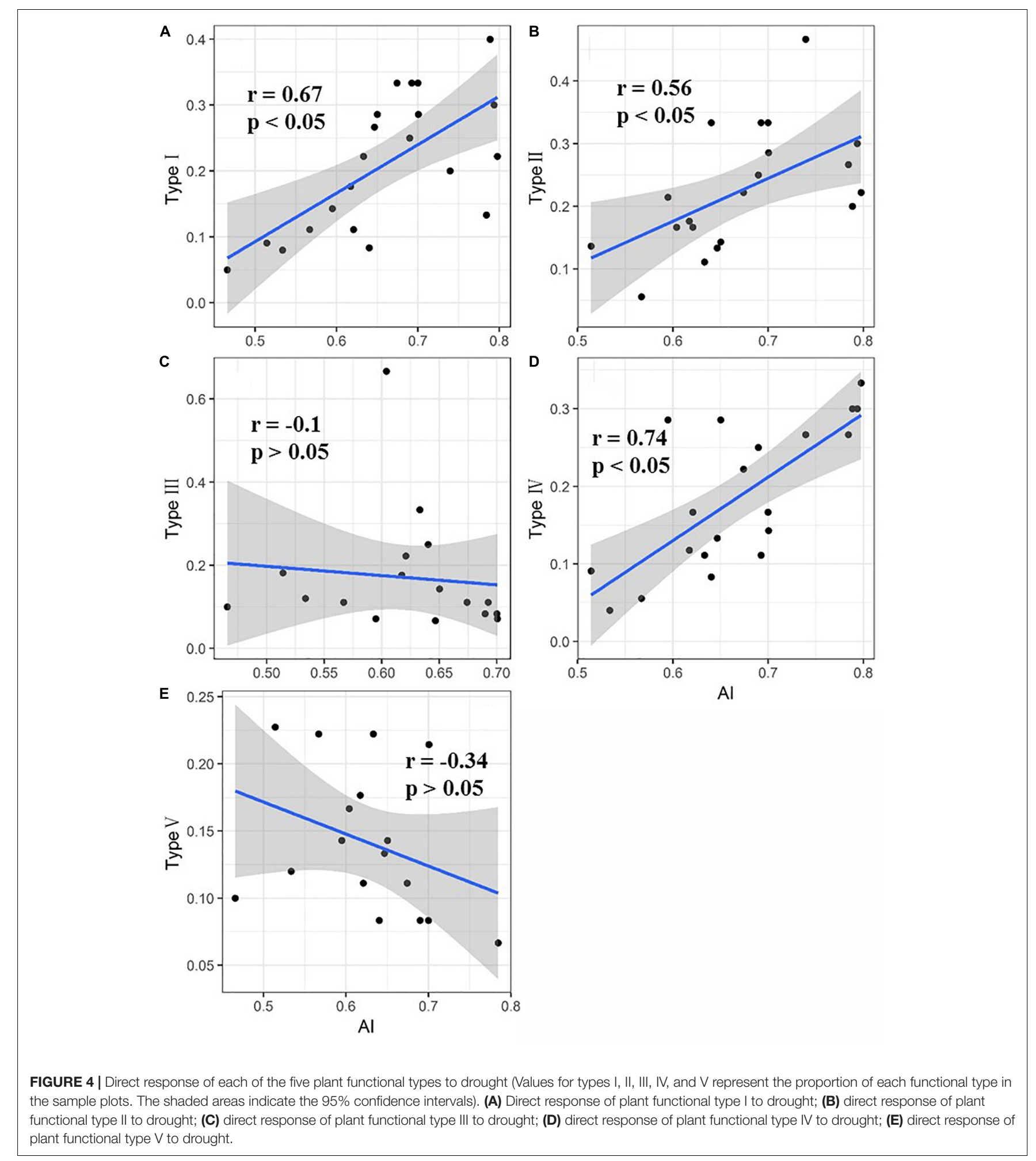

\section{Adaptation of Plants to Drought at the Functional Level}

The relationship between the proportion of each functional type at each site and the aridity is shown in Figure 4. The proportion of functional types I, II, and IV in the sample plots significantly increased as the aridity increased, while the proportion of functional types III and V tended to decrease but not significantly. Functional type I plants exhibited a simultaneous reduction in leaf area and leaf nitrogen content with the increase of 


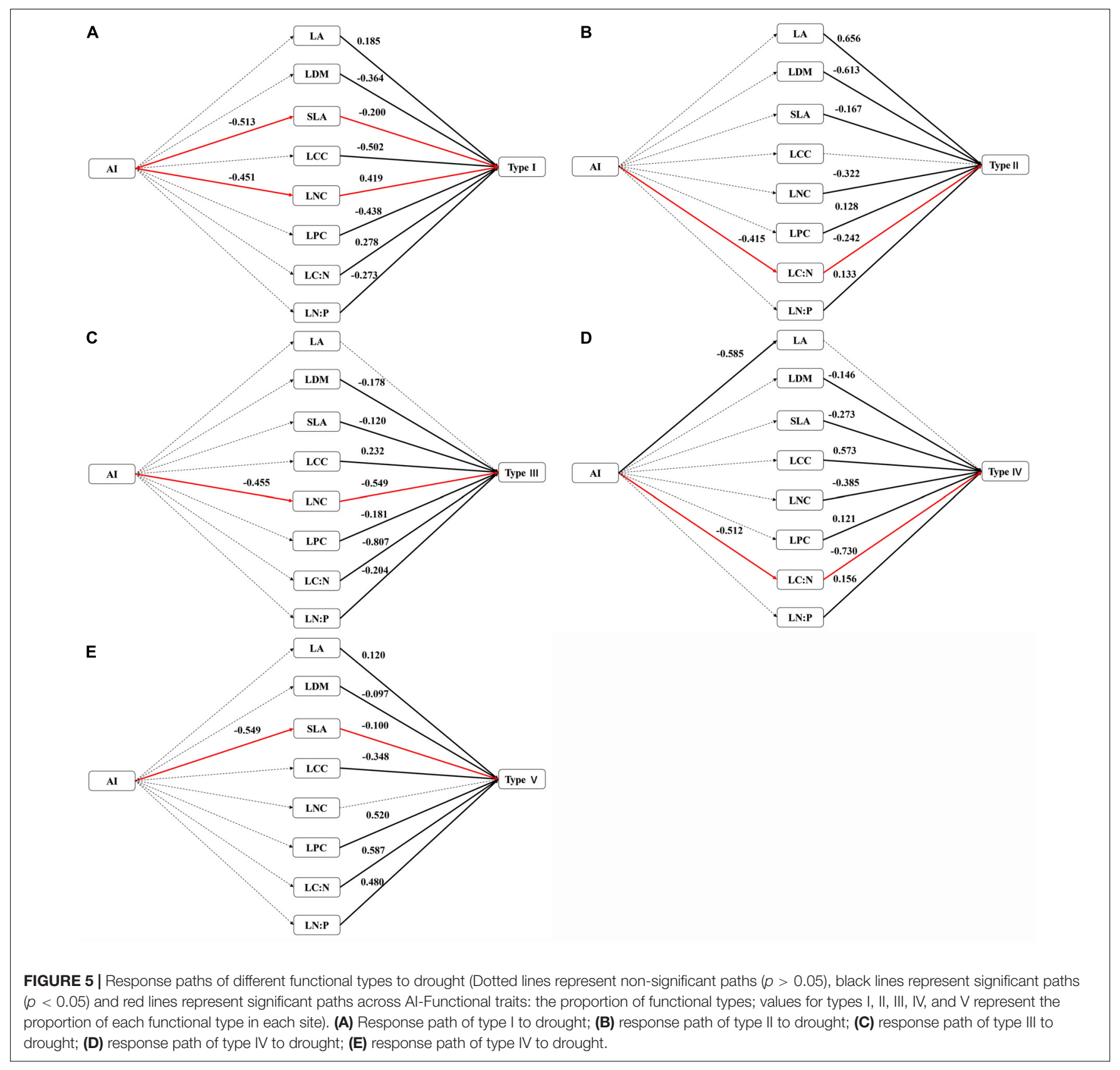

aridity (Figure 5A), while functional type II plants reduced the carbon-nitrogen ratio in their leaves (Figure 5B), functional type III plants increased their leaf nitrogen content (Figure 5C), functional type IV plants reduced the leaf carbon-nitrogen ratio in their leaves (Figure 5D) and functional type $\mathrm{V}$ plants reduced the leaf nitrogen content (Figure 5E) in response to drought.

\section{DISCUSSION}

In the present study, we demonstrated that aridity significantly affected the plant specific leaf area, leaf carbon content and leaf carbon-nitrogen ratio at the species level in the Inner
Mongolia grassland, which is consistent with the findings of previous studies which found that plants can adapt to drought by regulating their leaf functional traits (Wright et al., 2004; Jung et al., 2014; Valencia et al., 2015). Some studies have also demonstrated that phylogeny would impact the functional traits, i.e., species with close phylogenetic relationships have similar functional traits (Ackerly, 2009; Burns and Strauss, 2012). Similarly, we found that the single leaf area, specific leaf area and leaf carbon-nitrogen ratio were significantly affected by phylogeny at the species level, suggesting that these three functional traits may be "conserved traits" that have a have strong phylogenetic signal (Blomberg et al., 2003). Our finding that these three functional traits were significantly 
affected by both phylogeny and drought suggests that species with adaptive functional traits are selected for and retained under long-term, strong environmental filtering, supporting the findings of previous studies (Grether, 2005; Liu et al., 2013). Further analysis showed that the variation in leaf area could be better explained by phylogeny than by climatic factors, while the specific leaf area and leaf carbon-nitrogen ratio were mainly affected by climatic factors, demonstrating that the importance of phylogeny and climatic factors differs between different functional traits.

Many studies have reported that plants adapt to drought conditions by adjusting leaf functional traits in various ways, such as the leaf dry matter content, specific leaf area, leaf carbon, nitrogen and phosphorus contents, and leaf stoichiometric ratio (Hameed et al., 2012; Stropp et al., 2017). In the present study, we found that plants in the Inner Mongolia grassland adapted to drought mainly by adjusting their leaf carbonnitrogen ratios, specific leaf area and leaf nitrogen contents (Figure 5). Plant functional types II and IV showed the same adaptive strategy to drought, by decreasing the carbonnitrogen ratio and then increasing in proportion in the sample plot (Figures 4,5). The carbon-nitrogen ratio of plant leaves reflects the growth rate of plants to a certain extent, as a large amount of proteins, chlorophyll and rRNA are required for plant growth which, in turn, require large amounts of nitrogen and phosphorus, reducing the carbon-nitrogen ratio in the leaves (Agren, 2004). The leaves of functional type II species contained higher nitrogen and phosphorus contents than those of the other functional types (Figure 2), indicating that these plants can increase their growth rate by increasing their photosynthetic capacity, allowing them to eventually adapt to drought conditions. By contrast, the leaves of functional type IV plants had relatively low nitrogen and phosphorus contents but relatively high carbon contents (Figure 2), indicating that they could accumulate dry matter quite efficiently to adapt to drought conditions. Functional type $\mathrm{V}$ plants experienced a decrease in specific leaf area in response to drought (Figures $4 \mathrm{E}$, $5 \mathrm{E}$ ), which is speculated to increase water retention and thereby reduce transpiration and facilitate heat dissipation (Ackerly et al., 2002; Hameed et al., 2012). Finally, functional type III plants adapted to drought by increasing their leaf nitrogen content (Figure 5C), which is commonly associated with a high resource-acquisition capacity (Weih et al., 2011; Jung et al., 2014). This functional type mainly included species such as Leymus chinensis and Stipa grandis, which tend to predominate in areas with relatively abundant water (Inner Mongolia-Ningxia Joint Inspection Group of Chinese Sciences of Academy, 1985). However, the grassland in Inner Mongolia generally lacks nitrogen (Yuan et al., 2006), so the ability of these plants to obtain more nitrogen will be crucial for their adaptation to arid environments.

Numerous studies have documented that plants adapt to the environment by balancing resource utilization and allocation when resources are scarce (Gong et al., 2011; Ocheltree et al., 2016). In the present study, we found that functional type I plants exhibited a significant decrease in specific leaf area and leaf nitrogen content with an increase in aridity. A decrease in specific leaf area indicates an increased water use efficiency of plants (Ackerly et al., 2002), while a decrease in leaf nitrogen content indicates a lower nitrogen use efficiency (Yuan et al., 2006). Thus, this finding suggests that functional type I plants adapted to drought by trade-offs water use efficiency against nitrogen use efficiency. This result is consistent with the findings of Gong et al. (2011), who reported trade-offs between water use efficiency and nitrogen use efficiency in a semi-arid grassland. In areas with a high water supply, plants can improve their nitrogen use efficiency at the expense of water use efficiency. However, when water is restricted, it is a better strategy to improve water use efficiency to allow plants to increase dry matter accumulation, prolong their leaf life and complete their life cycle. Leaf thickness also tends to increase with a decrease in specific leaf area (Niinemets, 2001), further limiting the light intensity that reaches the chloroplasts inside the leaves, increasing the conduction resistance of $\mathrm{CO}_{2}$ in the mesophyll tissues and reducing the proportion of nitrogen that is distributed to the photosynthetic organs (Poorter and Evans, 1998), thereby decreasing the nitrogen content in the leaves.

In summary, our study demonstrated that plants in the Inner Mongolia grassland adapt to drought in four different ways including adjusting the leaf carbon-nitrogen ratio, the specific leaf area, the leaf nitrogen content, as well as the specific leaf area and leaf nitrogen content simultaneously. This finding is consistent with the LES which runs from species with conservative resource-use strategy to predominant resourceacquisition strategy (Wright et al., 2004). Functional type II, III, and IV plants adjusted their leaf nitrogen contents and carbonnitrogen ratios and thus correspond to conservative resource-use strategy plants, while functional type $\mathrm{V}$ plants adjusted their specific leaf area, corresponding with predominantly resourceacquisition strategy plants, and functional type I plants adjusted their specific leaf area and nitrogen content simultaneously indicate that the trade-offs in the LES. Thus, it is clear that the LES exists in the Inner Mongolia grassland and can be applied to reveal the adaptation of plants to drought.

\section{AUTHOR CONTRIBUTIONS}

QZ and YD conceived the ideas. YY and YL complied the experiments and ran further data analysis. YY, YL, QL, QZ, and YD led the writing.

\section{FUNDING}

This research is supported by National Basic Research program of China (Grant Nos. 31560180 and 31760150), Inner Mongolia Science and Technology Plan (Grant No. 201601061) and Postdoctoral Science Foundation (Grant No. 156409).

\section{ACKNOWLEDGMENTS}

Thanks to Ling Zhu and Yayuan Yan for the help of field work. 


\section{REFERENCES}

Abrahamson, W. G. (2007). Leaf traits and leaf life spans of two xericadapted palmettos. Am. J. Bot. 94, 1297-1308. doi: 10.3732/ajb.94. 8.1297

Ackerly, D. (2009). Conservatism and diversification of plant functional traits: evolutionary rates versus phylogenetic signal. Proc. Natl. Acad. Sci. U.S.A. 106, 19699-19706. doi: 10.1073/pnas.0901635106

Ackerly, D. D., Knight, C. A., Weiss, S. B., Barton, K., and Starmer, K. P. (2002). Leaf size, specific leaf area and microhabitat distribution of chaparral woody plants: contrasting patterns in species level and community level analyses. Oecologia 130, 449-457. doi: 10.1007/s004420100805

Agren, G. I. (2004). The C : N : P stoichiometry of autotrophs - theory and observations. Ecol. Lett. 7, 185-191. doi: 10.1111/j.1461-0248.2004.00567.x

Albert, C. H., Thuiller, W., Yoccoz, N. G., Soudant, A., Boucher, F., Saccone, P., et al. (2010). Intraspecific functional variability: extent, structure and sources of variation. J. Ecol. 98, 604-613. doi: 10.1111/j.1365-2745.2010.01651.x

Balvanera, P., Pfisterer, A. B., Buchmann, N., He, J.-S., Nakashizuka, T., Raffaelli, D., et al. (2006). Quantifying the evidence for biodiversity effects on ecosystem functioning and services. Ecol. Lett. 9, 1146-1156. doi: 10.1111/j. 1461-0248.2006.00963.x

Blomberg, S. P., Garland, T., and Ives, A. R. (2003). Testing for phylogenetic signal in comparative data: behavioral traits are more labile. Evolution 57, 717-745. doi: 10.1111/j.0014-3820.2003.tb00285.x

Bosabalidis, A. M., and Kofidis, G. (2002). Comparative effects of drought stress on leaf anatomy of two olive cultivars. Plant Sci. 163, 375-379. doi: 10.1016/s01689452(02)00135-8

Bowman, R. A. (1988). A rapid method to determine total phosphorus in soils. Soil Sci. Soc. Am. J. 52, 1301-1304. doi: 10.2136/sssaj1988.03615995005200050016x

Bu, W., Schmid, B., Liu, X., Li, Y., Härdtle, W., Oheimb, G. V., et al. (2017). Interspecific and intraspecific variation in specific root length drives aboveground biodiversity effects in young experimental forest stands. J. Plant Ecol. 10, 158-169. doi: 10.1093/jpe/rtw096

Burns, J. H., and Strauss, S. Y. (2012). Effects of competition on phylogenetic signal and phenotypic plasticity in plant functional traits. Ecology 93, S126-S137. doi: 10.1890/11-0401.1

Chapin, F. S. III, Bret-Harte, M. S., Hobbie, S. E., and Zhong, H. (1996). Plant functional types as predictors of transient responses of arctic vegetation to global change. J. Veg. Sci. 7, 347-358. doi: 10.2307/3236278

Chaves, M. M., Pereira, J. S., Maroco, J., Rodrigues, M. L., Ricardo, C. P. P., Osorio, M. L., et al. (2002). How plants cope with water stress in the field. Photosynthesis and growth. Ann. Bot. 89, 907-916. doi: 10.1093/aob/ $\operatorname{mcf} 105$

Cornelissen, J., Lavorel, S., Garnier, E., Diaz, S., Buchmann, N., Gurvich, D., et al. (2003). A handbook of protocols for standardised and easy measurement of plant functional traits worldwide. Aust. J. Bot. 51, 335-380. doi: 10.1071/ BT02124

Delgado-Baquerizo, M., Maestre, F. T., Gallardol, A., Bowker, M. A., Wallenstein, M. D., Luis Quero, J., et al. (2013). Decoupling of soil nutrient cycles as a function of aridity in global drylands. Nature 502, 672-676. doi: 10.1038/ nature 12670

Domínguez, M. T., Aponte, C., Pérez-Ramos, I. M., García, L. V., Villar, R., and Marañón, T. (2012). Relationships between leaf morphological traits, nutrient concentrations and isotopic signatures for mediterranean woody plant species and communities. Plant Soil 357, 407-424. doi: 10.1007/s11104-012-1214-7

Gong, X. Y., Chen, Q., Dittert, K., Taube, F., and Lin, S. (2011). Nitrogen, phosphorus and potassium nutritional status of semiarid steppe grassland in Inner Mongolia. Plant Soil 340, 265-278. doi: 10.1007/s11104-010-0577-x

Grether, G. F. (2005). Environmental change, phenotypic plasticity, and genetic compensation. Am. Nat. 166:E115. doi: 10.1086/432023

Hameed, M., Batool, S., Naz, N., Nawaz, T., and Ashraf, M. (2012). Leaf structural modifications for drought tolerance in some differentially adapted ecotypes of blue panic (Panicum antidotale Retz.). Acta Physiol. Plant. 34, 1479-1491. doi: 10.1007/s11738-012-0946-6

He, M., and Dijkstra, F. A. (2014). Drought effect on plant nitrogen and phosphorus: a metaanalysis. New Phytol. 204, 924-931. doi: 10.1111/nph.12952
Ian, W. F., and Wolgang, C. (2010). Plant functional types and climatic changes: introduction. J. Veg. Sci. 7, 306-308.

Inner Mongolia-Ningxia Joint Inspection Group of Chinese Sciences of Academy (1985). Vegetation of Inner Mongolia. Beijing: Science Publishing House.

Jung, V., Albert, C. H., Violle, C., Kunstler, G., Loucougaray, G., and Spiegelberger, T. (2014). Intraspecific trait variability mediates the response of subalpine grassland communities to extreme drought events. J. Ecol. 102, 45-53. doi: $10.1111 / 1365-2745.12177$

Kaplan, J. M., and Pigliucci, M. (2001). Genes for phenotypes: a modern history view. Biol. Philos. 16, 189-213. doi: 10.1023/A:1006773112047

Liu, B. B., Li, M., Li, Q. M., Cui, Q. Q., Zhang, W. D., Ai, X. Z., et al. (2018). Combined effects of elevated CO2 concentration and drought stress on photosynthetic performance and leaf structure of cucumber (Cucumis sativus L.) seedlings. Photosynthetica 56, 942-952. doi: 10.1007/s11099-0170753-9

Liu, X., Swenson, N. G., Zhang, J., and Ma, K. (2013). The environment and space, not phylogeny, determine trait dispersion in a subtropical forest. Funct. Ecol. 27, 264-272. doi: 10.1111/1365-2435.12018

Lohbeck, M., Poorter, L., Lebrija-Trejos, E., Martinez-Ramos, M., Meave, J. A., Paz, H., et al. (2013). Successional changes in functional composition contrast for dry and wet tropical forest. Ecology 94, 1211-1216. doi: 10.1890/ $12-1850.1$

Losos, J. B. (2008). Phylogenetic niche conservatism, phylogenetic signal and the relationship between phylogenetic relatedness and ecological similarity among species. Ecol. Lett. 11, 995-1003. doi: 10.1111/j.1461-0248.2008.01229.x

Lu, Y., Duan, B., Zhang, X., Korpelainen, H., and Li, C. (2009). Differences in growth and physiological traits of Populus cathayana populations as affected by enhanced UV-B radiation and exogenous ABA. Environ. Exp. Bot. 66, 100-109. doi: 10.1016/j.envexpbot.2008.12.006

Montes-Pulido, C. R., Parrado-Rosselli, A., and Alvarez-Davila, E. (2017). Palnt functional types as estimator of carbon in dry forest of the Colombian Caribbean. Rev. Mex. Biodivers. 88, 241-249. doi: 10.1016/j.rmb.2017.01.006

Narisma, G. T., Foley, J. A., Licker, R., and Ramankutty, N. (2007). Abrupt changes in rainfall during the twentieth century. Geophys. Res. Lett. 34:L06710. doi: $10.1029 / 2006 \mathrm{gl} 028628$

Niinemets, U. (2001). Global-scale climatic controls of leaf dry mass per area, density, and thickness in trees and shrubs. Ecology 82, 453-469. doi: 10.2307/ 2679872

Ocheltree, T. W., Nippert, J. B., and Prasad, P. V. V. (2016). A safety vs efficiency trade-off identified in the hydraulic pathway of grass leaves is decoupled from photosynthesis, stomatal conductance and precipitation. New Phytol. 210, 97-107. doi: 10.1111/nph.13781

Osnas, J. L. D., Lichstein, J. W., Reich, P. B., and Pacala, S. W. (2013). Global leaf trait relationships: mass, area, and the leaf economics spectrum. Science 340 , 741-744. doi: 10.1126/science.1231574

Picotte, J. J., Rhode, J. M., and Cruzan, M. B. (2009). Leaf morphological responses to variation in water availability for plants in the Piriqueta caroliniana complex. Plant Ecol. 200, 267-275. doi: 10.1007/s11258-008-9451-9

Pie, M. R., and Weitz, J. S. (2005). A null model of morphospace occupation. Am. Nat. 166, E1-E13. doi: 10.1086/430727

Poorter, H., and Evans, J. R. (1998). Photosynthetic nitrogen-use efficiency of species that differ inherently in specific leaf area. Oecologia 116, 26-37. doi: 10.1007/s004420050560

Ramirez-Valiente, J. A., Koehler, K., and Cavender-Bares, J. (2015). Climatic origins predict variation in photoprotective leaf pigments in response to drought and low temperatures in live oaks (Quercus series Virentes). Tree Physiol. 35, 521-534. doi: 10.1093/treephys/tpv032

Semenova, G. V., and van der Maarel, E. (2000). Plant functional types - a strategic perspective. J. Veg. Sci. 11, 917-922. doi: 10.2307/3236562

Shavrukov, Y., Kurishbayev, A., Jatayev, S., Shvidchenko, V., Zotova, L., Koekemoer, F., et al. (2017). Early flowering as a drought escape mechanism in plants: how can it aid wheat production? Front. Plant Sci. 8:1950. doi: 10. 3389/fpls.2017.01950

Shipley, B., Lechowicz, M. J., Wright, I., and Reich, P. B. (2006). Fundamental trade-offs generating the worldwide leaf economics spectrum. Ecology 87, 535-541. doi: 10.1890/05-1051 
Silva, I. A., and Batalha, M. A. (2011). Plant functional types in Brazilian savannas: the niche partitioning between herbaceous and woody species. Perspect. Plant Ecol. Evol. Syst. 13, 201-206. doi: 10.1016/j.ppees.2011.05.006

Stropp, J., dos Santos, I. M., Correia, R. A., dos Santos, J. G., Silva, T. L. P., dos Santos, J. W., et al. (2017). Drier climate shifts leaf morphology in Amazonian trees. Oecologia 185, 525-531. doi: 10.1007/s00442-017-3964-7

Tanaka, Y., and Shiraiwa, T. (2009). Stem growth habit affects leaf morphology and gas exchange traits in soybean. Ann. Bot. 104, 1293-1299. doi: 10.1093/aob/ mcp 240

Valencia, E., Maestre, F. T., Le Bagousse-Pinguet, Y., Quero, J. L., Tamme, R., Borger, L., et al. (2015). Functional diversity enhances the resistance of ecosystem multifunctionality to aridity in Mediterranean drylands. New Phytol. 206, 660-671. doi: 10.1111/nph.13268

Webb, C. O., Ackerly, D. D., McPeek, M. A., and Donoghue, M. J. (2002). Phylogenies and community ecology. Annu. Rev. Ecol. Syst. 33, 475-505. doi: 10.1146/annurev.ecolysis.33.010802.150448

Weih, M., Bonosi, L., Ghelardini, L., and Ronnberg-Wastljung, A. C. (2011). Optimizing nitrogen economy under drought: increased leaf nitrogen is an acclimation to water stress in willow (Salix spp.). Ann. Bot. 108, 1347-1353. doi: $10.1093 / \mathrm{aob} / \mathrm{mcr} 227$

Wright, I. J., Reich, P. B., Cornelissen, J. H. C., Falster, D. S., Garnier, E., Hikosaka, K., et al. (2005). Assessing the generality of global leaf trait relationships. New Phytol. 166, 485-496. doi: 10.1111/j.1469-8137.2005.01349.x

Wright, I. J., Reich, P. B., Westoby, M., Ackerly, D. D., Baruch, Z., Bongers, F., et al. (2004). The worldwide leaf economics spectrum. Nature 428, 821-827. doi: $10.1038 /$ nature 02403

Wu, J., Zhang, Q., Li, A., and Liang, C. (2015). Historical landscape dynamics of Inner Mongolia: patterns, drivers, and impacts. Landsc. Ecol. 30, 1579-1598. doi: 10.1007/s10980-015-0209-1
Yuan, Z. Y., Li, L. H., Han, X. G., Chen, S. P., Wang, Z. W., Chen, Q. S., et al. (2006). Nitrogen response efficiency increased monotonically with decreasing soil resource availability: a case study from a semiarid grassland in northern China. Oecologia 148, 564-572. doi: 10.1007/s00442-0060409-0

Zhang, H., Li, W., Adams, H. D., Wang, A., Wu, J., Jin, C., et al. (2018). Responses of woody plant functional traits to nitrogen addition: a meta-analysis of leaf economics, gas exchange, and hydraulic traits. Front. Plant Sci. 9:683. doi: 10.3389/fpls.2018. 00683

Zhang, L. X., Ma, D., Xu, J. S., Quan, J. X., Dang, H., Chai, Y. F., et al. (2017). Economic trade-offs of hydrophytes and neighbouring terrestrial herbaceous plants based on plant functional traits. Basic Appl. Ecol. 22, 11-19. doi: 10.1016/ j.baae.2017.06.004

Zhu, Y., Kang, H., Xie, Q., Wang, Z., Yin, S., and Liu, C. (2012). Pattern of leaf vein density and climate relationship of Quercus variabilis populations remains unchanged with environmental changes. Trees 26, 597-607. doi: 10.1007/s00468-011-0624-0

Conflict of Interest Statement: The authors declare that the research was conducted in the absence of any commercial or financial relationships that could be construed as a potential conflict of interest.

Copyright (C) 2019 Yan, Liu, Zhang, Ding and Li. This is an open-access article distributed under the terms of the Creative Commons Attribution License (CC BY). The use, distribution or reproduction in other forums is permitted, provided the original author(s) and the copyright owner(s) are credited and that the original publication in this journal is cited, in accordance with accepted academic practice. No use, distribution or reproduction is permitted which does not comply with these terms. 